\title{
HISTÓRIA DAS IDEIAS LINGUÍSTICAS E ANÁLISE DO DISCURSO: O CORTE EPISTEMOLÓGICO
}

\section{HISTORY OF LINGUISTIC IDEAS AND DISCOURSE ANALYSIS: EPISTEMOLOGICAL BREAK}

\author{
Lauro Baldini \\ Instituto de Estudos da Linguagem (IEL), Unicamp, Campinas, SP, Brasil \\ Thales de Medeiros Ribeiro ${ }^{1}$ \\ Instituto de Estudos da Linguagem (IEL), Unicamp, Campinas, SP, Brasil \\ Karine de Medeiros Ribeiro ${ }^{2}$ \\ Instituto de Estudos da Linguagem (IEL), Unicamp, Campinas, SP, Brasil
}

\begin{abstract}
Resumo: Neste artigo, objetivamos apresentar impasses sobre a concepçâo de história e ciência para a História das Ideias Linguísticas e para a Análise do Discurso, focalizando a problemática do corte epistemológico (particularmente do "corte saussuriano").
\end{abstract}

Palavras-chave: Análise do Discurso; História das Ideias Linguísticas; corte epistemológico.

Abstract: In this article, we present impasses about the conception of history and science for the History of Linguistic Ideas and for Discourse Analysis, focusing on the problematic of the epistemological break (particularly the "Saussurian break").

Keywords: Discourse Analysis; History of Linguistic Ideas; epistemological break.

Pêcheux : Je voudrais revenir un instant sur ce que vient de dire GADET : la linguistique a un statut assez singulier. C'est au fond ce qui nous a amenés à travailler sur les thèmes abordés dans La langue introuvable et sur la crise de la linguistique. [...] Je m'en tiens donc à ta première question : comment est-on passé de l'élucidation de cette conjoncture actuelle à la nécessité de faire l'histoire de la linguistique ? La réponse est peut-être qu'au fond la linguistique est une science humaine très particulière... dans la mesure où, probablement, elle n'en est pas une. Elle a en effet cette propriété tout à fait paradoxale [...] que son existence se soutient du privilège d'avoir un objet, face aux sciences humaines qui en construisent à volonté. Mais ce privilège de la linguistique, tout se passe comme si son "cours", son évolution historique, avaient pour effet [...] de lui faire négliger, recouvrir, barrer. Ce qui amène à se poser la question de la nature des découvertes linguistiques, et de leur statut par rapport à ce des-

\footnotetext{
${ }^{1}$ Bolsista CNPq-Brasil.

2 Bolsista CNPq-Brasil.
} 
tin de recouvrement irrésistible. Sur Saussure aussi bien que sur Chomsky, nous avons trouvé des éléments susceptibles d'étayer cette thèse. Du point de vue de la référence à l'histoire, cela conduit à confronter le rapport entre une histoire interne, non pas simplement une histoire des concepts d'une discipline, mais de ses pratiques et des pratiques auxquelles cette discipline se réfere. Je voudrais donner des exemples, [...] comme d'une part, les différences socio-historiques dans les conditions d'enseignement ou de non-enseignement de la grammaire comme pratique scolaire de transmission : d'autre part les formes d'inscription ou de réinscription philosophique qui s'effectuent dans l'itinéraire du chomskisme. Dans les deux cas, nous étions obligés de nous poser la question (et c'est alors là peut-être que le marxisme a quelque chose à voir, positivement ou négativement, c'est-à-dire de toute façon sous la forme d'une interrogation) $d u$ rapport entre une histoire internet (contenant un certain nombre d'événements qui n'intéressent que la sphère de la linguistique) et "l'histoire de la lutte des classes". (DISCUSSION, 1980, p. 392-393, grifo nosso).

Este artigo está inserido no quadro teórico-metodológico da História das Ideias Linguísticas em diálogo com conceitos e dispositivos da Análise do Discurso. Ao considerar a produtividade específica da relaçáo entre as duas disciplinas - que, como veremos, não se confunde com uma leitura interdisciplinar da história - é possível depreender um gesto de leitura das condiçôes de produção dos discursos ditos científicos. Destacamos que, "no Brasil, a História das Ideias Linguísticas teve início por meio de uma colaboração entre a Universidade Estadual de Campinas e a Universidade Paris 7, na França" (NUNES, 2008, p. 109). Contudo, ambas as disciplinas têm bases teóricas diferentes e produziram interpretaçôes específicas sobre a ciência linguística e o legado teórico e político de Saussure.

Partindo de debates sobre o "corte epistemológico", objetivamos situar alguns impasses entre as concepçóes de história e ciência da História das ideias Linguísticas e da Análise do Discurso de Pêcheux. Pretendemos ainda condensar uma série de discussóes e questionamentos produzidos no percurso teórico desse autor em torno dos efeitos do corte saussuriano no corpo socio-histórico da Linguística.

Gostaríamos de iniciar nosso debate sobre o amplo tema do "corte epistemológico" no campo da Linguística com uma intervenção pouco conhecida de Pêcheux. O colóquio Pourquoi et comment faire l'histoire des sciences humaines foi organizado e apresentado por Normand e ocorreu entre os dias 28 e 30 de maio de 1980 em Paris-X (Nanterre). O evento reuniu historiadores e filósofos de diferentes grupos de pesquisa em torno 
de cinco sessôes de comunicação ${ }^{3}$. Vale destacar que a noção de "ruptura epistemológica" e a de "revolução científica" foram questóes privilegiadas durante todo o colóquio. A efervescente discussão entre leitores tâo célebres da obra de Saussure, como Derrida, Puech, Chiss, Normand e Pêcheux, parece um sintoma da verdadeira incomensurabilidade das posiçóes teóricas em jogo nessa conjuntura. Atendo-nos à posição defendida por Pêcheux em nossa epígrafe, a Linguística seria uma ciência humana muito particular em relação a campos que autoproclamam sua cientificidade. Seguindo a via materialista, Pêcheux argumenta que a Linguística se constituiu na medida em que construiu para si um objeto. No entanto, tudo se passa como se seu "curso", sua evolução histórica, tivesse o efeito paradoxal de recobrir, barrar ou negligenciar a sua fundaçáo, fato que o conduz a produzir uma interrogação sobre a relação entre uma história "interna" da ciência e a "história da luta de classes" ". O reconhecimento da descontinuidade no processo de produção do saber linguístico não se confunde com o preconceito partilhado de "querer fazer a história da linguistica concebida como uma ciência, isto é, como uma forma de saber cuja organização e cujas propriedades seriam estáveis" (AUROUX, 2009, p. 12, grifo do autor), pois é exatamente no interior da Linguística que Gadet e Pêcheux ([1977] 2011) investem a leitura da continuidade da "filosofia espontânea dos linguistas". Nesse sentido, o tema do corte epistemológico, bem como a especificidade da história do "recente" (instituiçôes, revistas, órgãos de fomento etc.) são problemas ainda abertos a releituras e a questionamentos.

O historiador Auroux apresenta, no recente artigo $O$ que pode dizer um historiador da ciência sobre Saussure?, um argumento que, à primeira vista, pode manter uma relaçáo de semelhança com os apontamentos feitos anteriormente por Pêcheux no tocante à definição do objeto da Linguística:

O que interessa aos linguistas da sincronia é que a língua enquanto tal é idêntica a si mesma. Trata-se de uma redefinição do campo do objeto. A definição do objeto ele mesmo pode ser considerada como uma inovação. Qualquer que

\footnotetext{
${ }^{3}$ As mesas foram organizadas de acordo com os seguintes temas: 1) historicidade das ciências humanas; 2) as formas de racionalidade nas ciências humanas; 3) ensinar uma teoria com ou sem sua história; 4) os filósofos "diante" das ciências humanas; e 5) normatividade e ciências humanas. As atas do colóquio contendo as apresentaçôes e discussóes das cinco mesas temáticas foram publicadas em dois números especiais da revista Linx (1980) sob o título Les Sciences Humaines: Quelle Histoire ?!!. Nesse contexto, Gadet e Pêcheux apresentaram um artigo " La linguistique hors d'elle-même: l'histoire absolument" na mesa "Les Philosophes 'devant' les sciences humaines ", comentando aspectos analisados no livro La langue introuvable (1981).

${ }^{4}$ Sobre esse assunto, cf. Pêcheux (1998).
} 
seja, uma invençáo depende unicamente da retomada pelo seu estado posterior da disciplina. Sabemos hoje que ela não é unânime, mas que se trata da inovação, a mais original inovaçáo do referido linguista (AUROUX, 2017, p. 178 , grifo nosso).

Feitas essas consideraçóes, deixamos a advertência de que, apesar de constituir, no Brasil, uma relação de produtividade específica, as duas disciplinas não partem dos mesmos pressupostos teórico-epistemológicos.

Antes mesmo de falar da especificidade do corte epistemológico no campo da Linguística para as duas disciplinas, é necessário regressar aos fundamentos das duas posiçóes teóricas em relaçáo aos conceitos de história e de ciência. Uma das marcas de tal produtividade talvez consista na possibilidade aberta pelo materialismo histórico de intervir a partir do questionamento sobre a teoria do objeto da História das Ideias Linguísticas.

Falando de modo brutal, a história vive na ilusāo de que pode dispensar a teoria, no sentido estrito a teoria do seu objeto, e, portanto, dispensar uma definição do seu objeto. O que lhe serve de teoria, o que, a seu ver, assume o lugar dela, é a metodologia, isto é, as normas que lhe regem as práticas efetivas, práticas centradas na crítica dos documentos e na restauraçáo dos fatos. O que nela assume o lugar de objeto teórico é, a seu ver, o objeto "concreto". A história toma, pois, a sua metodologia pela teoria que lhe falta, e toma o "concreto" das evidências concretas do tempo ideológico pelo objeto teórico.

Essa dupla confusáo é típica de uma ideologia empirista. O que falta à história é o enfrentamento consciente e corajoso de um problema essencial a qualquer ciência: o problema da natureza e da constituiçáo de sua teoria. Entendo por isso a teoria interior à própria ciência, o sistema dos conceitos teóricos que fundamenta qualquer método e toda prática, inclusive experimental, e que ao mesmo tempo define o seu objeto teórico. Ora, salvo exceçôes, os historiadores nẫo enfrentam o problema vital e urgente para a história: o problema da teoria da história. E como acontece inevitavelmente, o lugar deixado vazio pela teoria científica é ocupado por uma teoria ideológica, cujos efeitos nefastos podem exibir-se, até no pormenor, no próprio plano da metodologia dos historiadores (ALTHUSSER, 1980, p. 50, itálico do autor, negrito nosso).

Em A Revolução Tecnológica da Gramatização, Auroux (2009) afirma que o conhecimento é uma realidade histórica e seu modo de existência real é a temporalidade ramificada da constituiçáo cotidiana do saber. O saber, por sua vez, possui uma espessura temporal constituída por horizontes de retrospecção e horizontes de projeçấo, ou seja, uma memória e um projeto: 
O saber (as instâncias que o fazem trabalhar) não destrói seu passado como se crê erroneamente com frequência; ele o organiza, o escolhe, o esquece, o imagina ou o idealiza, do mesmo modo que antecipa seu futuro sonhando-o enquanto o constrói. Sem memória e sem projeto, simplesmente não há saber (AUROUX, 2009, p. 12).

Para Auroux (2009, p. 12, grifo do autor), "existe um halo de historicidade que engendra a retrospecção e a historicidade que constitui o ponto de vista do historiador". Ser historiador é colocar a si mesmo "a questão global da mudança (por que, como, quando) e da essência dos objetos submetidos à mobilidade em si e para si". Sobre esse aspecto, Pêcheux ([1969] 2011) argumenta que a oposição filosófica entre em si/para si se constitui como efeito ideológico que marca uma continuidade com o idealismo. Colocando em jogo as duas perspectivas, é importante destacar também a crítica de Pêcheux ([1975] 1995) ao imaginário da identificação (contínua) dos objetos de conhecimento aos objetos reais na visão empirista da história que mascara radicalmente qualquer descontinuidade epistemológica ${ }^{5}$. Baldini (2005) também aponta para a singularidade da tomada de posição teórica materialista de Althusser e Pêcheux, traçando uma diferença entre os fundamentos históricos desses autores e os três princípios teórico-metodológicos de Auroux. A crítica frontal de Baldini a Auroux incide sobre o lugar de uma

${ }^{5}$ Cf. o $11^{\circ}$ tópico de Althusser na introdução de Ler o Capital, "De O Capital à filosofia de Marx" (1979), em que o autor traça uma distinção entre o objeto real e o objeto de conhecimento. Em outra perspectiva teórica, Auroux (2017, 170-171, grifo nosso) sintetiza os elementos que constituiriam uma ciência para um historiador: "Para um historiador, a ciência é um domínio empírico, dotado da seguinte estrutura: i) os fatos são constituídos de conhecimento, quer dizer, de asserçóes consagradas a domínios de objetos e validados por protocolos empíricos e formais recuperáveis; ii) o conhecimento é invenção, isto é, inovaçáo retomada no horizonte de retrospecçáo da comunidade e verificável quando necessário; iii) o tempo é uma dimensão essencial das disciplinas científicas: náo há ciência instantânea nem ciência sem memória (ou horizonte de retrospecçáo); iv) o conhecimento é descontínuo (ele corresponde a invençóes isoláveis, mais ou menos datáveis e substanciais) e é igualmente inserido nos conjuntos mais vastos ou em campos de conhecimentos; v) a estrutura dos campos de conhecimentos pode variar, sem, para tanto, fazer desaparecer certas invençóes ou núcleos de racionalidade [...]; vi) novos objetos podem aparecer em um domínio de conhecimento ou dele desaparecer; esses fenômenos podem depender da estrutura do campo, de uma mudança de interesse ou do aparecimento de novos dados empíricos; vii) um domínio de conhecimento que náo tenha núcleos de racionalidade a longo termo não seria uma ciência. Os núcleos de racionalidade estáo submetidos à revisão, mas podem também ter reconhecidas suas filiaçóes ou sua recorrência; viii) as asserçōes fundadas sobre a estrutura de um campo de conhecimento em um dado momento náo têm nenhuma necessidade de serem estáveis. A ideia que temos de ciência (independentemente da abordagem histórica) faz parte desse tipo de asserção". 
dupla ausência no corpo teórico da História das Ideias Linguísticas: a falta da luta e divisão de classes e a falta do sujeito.

\begin{abstract}
Auroux não irá trazer para sua reflexáo a questáo de classe nem a questão do sujeito. Em que pese sua fineza e rigor teóricos, pode-se perceber ali uma falta (não no sentido de algo que deva ser preenchido, mas no sentido de escolha teórica): não há nenhuma menção ao problema do sujeito. O que há são homens que veem suas relaçôes com a língua alteradas de acordo com os saberes que sobre ela se constituem. A definição fenomenológica de Auroux, portanto, resvala para os dois lados: o homem e a língua. Se ele não irá diluir seu trabalho numa definição prévia de língua, também não irá levar em conta a definição de sujeito. Não haverá, então, nenhum problema a se colocar quanto à singularidade dos homens que fazem a história sobre a linguagem, uma vez que esta discussão está primacialmente eliminada juntamente com a questão do objeto desse saber, a língua. Nesse caso, a história que Auroux procura descrever e analisar é a história dos produtos daquilo que Althusser chama de efeitos ideológicos (BALDINI, 2005, p. 31, grifo do autor).
\end{abstract}

Dessa forma, somos conduzidos a problematizar como os três princípios metodológicos (definição puramente fenomenológica do objeto; neutralidade epistemológica; historicismo moderado) adotados por Auroux em sua leitura da constituição, criação, evolução, transformação e desaparecimento do saber linguístico podem suscitar um debate produtivo a partir da visada materialista da história na qual Pêcheux está inserido.

O historicismo moderado, ligado a uma perspectiva cognitivista da história, é uma espécie de "realismo metodológico que concede consistência ao saber e independência aos fenômenos [e as 'estratégias cognitivas'] em relação a esse saber" (AUROUX, 2009, p. 16, grifo do autor). A consequência da separação entre a consistência do saber linguístico e a realização dos fenômenos é a de que o valor de um saber - a "adequação a um fim dado, logo seu valor de verdade quando esse fim é a representação" (AUROUX, 2009, p. 16) - é uma causa em seu devir histórico. Nessa orientação, Auroux (2009, p. 16, itálico do autor, negrito nosso) argumenta que o historiador é necessariamente relativista, mas sempre está diante de "condiçóes objetivas que fazem com que esta ou aquela escolha - evidentemente imposta pelas condiçóes em que aparece - abra possibilidades diferentes segundo a natureza própria de seu conteúdo".

Se remontarmos à posição materialista formulada por Althusser em sua leitura filosófica do objeto científico de $\mathbf{O}$ Capital, podemos produzir um questionamento à complementaridade entre a objetividade do dado e 
o "relativismo" construídos a partir do "realismo metodológico". Em "O objeto de $O$ Capital", Althusser (1980, p. 46) toma partido pela necessidade de "purificar nosso conceito de teoria da história, de modo radical, de toda contaminação pelas evidências de história empírica, pois sabemos que essa 'história empírica' nada mais é que o aspecto desnudo da ideologia empirista da história”. Contra o peso da tentação empirista, o autor insiste na distinção radical de natureza spinozista entre a história e o conceito de história: "o conhecimento da história não é histórico, tanto quanto não é açucarado o conhecimento do açúcar" (ALTHUSSER, 1980, p. 46). Se a teoria da economia política pôde enunciar leis gerais tomando apenas uma parte relativamente autônoma da totalidade social, Marx, diferentemente, pôde fundar a ciência da história (o materialismo histórico) e a construçáo de um objeto completamente novo ao visar, em princípio, a partir da sua crítica à economia política, a totalidade complexa como tal por objeto. É nesse direcionamento preciso que o materialismo histórico é incomensurável com o "realismo" e com o "relativismo".

A construção do conceito de história é retomada em Semântica e Discurso quando Pêcheux ([1975] 1995) trata especificamente da inovação radical colocada pelo materialismo histórico (o objeto de $\mathbf{O}$ Capital e a abertura de um campo teórico novo, o "continente-história"). A fundação do materialismo histórico, definida como a ciência da história, impossibilita a existência de uma ciência "burguesa" da história: "Não há, pois, e não poderia existir, 'ciência burguesa' da história, o que, bem entendido, náo quer dizer, de modo algum, que, contra todas as aparências, a burguesia não faça política (!)" (PÊCHEUX, [1975] 1995, p. 203). Além disso, para o autor, as condiçốes de produção do discurso científico estão ligadas materialmente a um estado dado no processo de produção, sendo que tais condiçóes de produção e processos de produção são afetadas pela ideologia e pelo inconsciente.

Para Auroux (2009, p. 14, grifo do autor), é preciso, antes de tudo, "situar nosso objeto em relação só a um campo de fenômenos, apreensíveis à altura da consciência cotidiana. Seja a linguagem humana, tal como ela se realizou na diversidade das linguas; saberes se constituiram a seu respeito; este é nosso objeto". No posfácio intitulado "A fecundidade do conceito de gramatização", ao criticar as observaçôes foucaultianas sobre a Gramática

\footnotetext{
6 "Marx foi o primeiro a descobrir a grande lei do movimento da história, a lei segundo a qual todas as lutas históricas travadas no âmbito político, religioso, filosófico ou em qualquer outro campo ideológico são de fato apenas a expressão mais ou menos nítida de lutas entre classes sociais" (ENGELS, 2011, p. 22).
} 
Geral, Auroux considera que "devemos interrogar sobre um método [o de Foucault] que consiste, para o historiador, em definir abstratamente o que é historicamente possível ou impossível. Devemos sempre partir dos fatos" (AUROUX, 2009, p. 121). Uma diferença que podemos depreender daí, mas que não reside somente em sua crítica à compreensão histórica de Foucault, é o não reconhecimento no campo da História das Ideias Linguísticas da distinçáo radical entre objeto real e objeto de conhecimento (ALTHUSSER, 1979) e o imaginário de que o objeto é um dado, um fato reduzido à condição da "visão empírica".

Em História das Ideias Linguísticas, o princípio metodológico da neutralidade epistemológica - que difere da "neutralidade veridiccional" decorre imediatamente da forma de se abordar o objeto: "não faz parte de nosso papel dizer se isto é mais ciência do que aquilo, mesmo se nos acontecer de sustentar que isto ou aquilo é concebido como ciência, por esta ou aquela razão, segundo este ou aquele critério” (AUROUX, 2009, p. 14).

A partir da discussão sobre o princípio metodológico da "neutralidade epistemológica", podemos nos perguntar se há um "mascaramento da descontinuidade (e a relaçáo de simulaçáo) entre conhecimento científico e desconhecimento ideológico" (PÊCHEUX, [1975] 1995, p. 129) na visada de Auroux. Explicamos. Desde seus trabalhos em filosofia das ciências e das técnicas científicas, Balibar e Pêcheux ([1969] 1971, p. 11-12, grifo nosso), resumindo os elementos teóricos desenvolvidos por Regnault, tomam o corte epistemológico (termo althusseriano) como "ponto sem retorno" que "constitui uma tomada de posiçẫo na polêmica que opóe em epistemologia e em história das ciências a corrente 'continuísta' [...] à corrente 'descontinuísta' que podemos, por comodidade, designar pelos nomes de Bachelard e de Koyré". Tomando posição pela corrente descontinuísta, os autores distinguem $o$ corte epistemológico (que tem por efeito determinar uma autonomia relativa da nova ciência que lhe corresponde) das demarcaçôes ou rupturas intra-ideológicas (correçôes, críticas, refutações, negaçôes de certas ideologias ou filosofias precedentes).

O corte tem por efeito tornar impossíveis certos discursos ideológicos ou filosóficos que o precedem, quer dizer, conduzir a nova ciência a romper explicitamente com eles: a ruptura epistemológica surge assim como um efeito [...] do corte ([...] não basta romper com uma ideologia para produzir um corte) (BALIBAR; PÊCHEUX, [1969] 1971, p. 14, grifo dos autores). 
$\mathrm{O}$ conceito de corte náo corresponde a um projeto voluntarista de efetuar um "salto" para fora da ideologia no domínio científico, nem com a conotação religiosa que liga de forma inevitável a este projeto os "heróis da ciência”. Além disso, Balibar e Pêcheux ([1969] 1971, p. 16, grifo nosso) afirmam que a "utilização adequada deste conceito [de corte] exige sempre um trabalho epistemológico sobre a história da disciplina em estudo, referida ao campo diferencial da história das ciências".

As ciências colocam suas questôes, através da interpretação de instrumentos, de tal maneira que o ajustamento de um discurso científico a si mesmo consiste, em última instância, na apropriação dos instrumentos pela teoria. É isto que faz da atividade científica uma prática (HENRY, 2014, p. 16, grifo do autor).

Ao comentar o papel que é atribuído aos instrumentos científicos no artigo de Thomas Herbert ([1966] 2011), Henry (2014) afirma que cada vez que um instrumento é transferido de um ramo de uma ciência a outro, ou de uma ciência para outra, este instrumento é de alguma forma reinventado. O projeto de fundação de uma teoria do discurso como dispositivo de leitura das ideologias é materializado tanto nos textos de Pêcheux produzidos inicialmente no quadro da psicologia social (expandidos posteriormente para o campo específico da Linguística), quanto nos textos sobre história das ciências e das técnicas científicas em que o materialismo histórico é mobilizado ${ }^{7}$.

Os trabalhos de Thomas Herbert e Pêcheux ${ }^{8}$ podem ser aproximados,

\footnotetext{
${ }^{7} \mathrm{Na}$ época de formaçáo da Análise do Discurso no campo da filosofia das ciências, destacamos o artigo Idéologie et histoire dês sciences: les effets de la coupure galiléenne en physique et en biologie, publicado no livro Sur l'histoire des sciences, em que Pêcheux [(1969) 1971] defende as teses apresentadas por Althusser em um curso de filosofia para cientistas ministrado em 1967-1968. Entre as teses, podemos citar a linha de demarcação (ruptura) entre o ideológico das ideologias e o científico das ciências.

${ }^{8}$ Segundo Maldidier, a formaçấo da Análise do Discurso na França tem um uma "dupla fundação", por um lado, pelos trabalhos de Dubois e, por outro, de Pêcheux. Contudo, a autora destaca que ambos estavam tinham preocupaçóes teóricas distintas e se situavam em campos igualmente diversos. Se, do lado de Dubois, a instituição da Análise do Discurso é concebida como uma passagem "natural" do estudo das palavras (lexicologia) ao estudo do enunciado. Do lado de Pêcheux, a fundação da Análise do Discurso pode ser interpretada como um corte epistemológico com a ideologia dominante nas ciências humanas e sociais, tomando inicialmente a psicologia social como campo privilegiado de intervenção. Segundo o ponto de vista apresentado por Maldidier (2010, p. 13) "o objeto discurso, que reformula a fala saussuriana na sua relaçấo com a língua, implica, de acordo com a fórmula althusseriana, uma mudança de terreno".
} 
por exemplo, se lermos a proposta final de sua tese em que o autor relacionou seu projeto à leitura dos discursos científicos e à "identificação da 'ruptura epistemológica' entre uma ciência e o terreno de que ela se separa para se constituir" (PÊCHEUX, [1969] 1997, p. 150). Henry (1997) argumenta que a crítica de Pêcheux ao estado "pré-científico" das ciências humanas e sociais se aproxima, sobretudo, da epistemologia de Canguilhem e Bachelard, mas a redireciona à problemática da produção do conhecimento científico diante das consequências do caráter contraditório da combinação das forças produtivas e das relaçóes de produção em uma sociedade dividida em classes.

Se adentrarmos no campo diferencial e paradoxal das ciências da linguagem ${ }^{9}$, podemos destacar que um dos pontos de contato dessa articulação entre Análise do Discurso e História das Ideias Linguísticas "reside em uma visão história da ciência e, particularmente, do que chamamos as 'ciências da linguagem”" (NUNES, 2008, p. 109). Nesse sentido, ao tomar a expressão "ciências da linguagem" no plural, marca-se a diversidade dos estudos da linguagem que devem ser considerados.

Embora a chamada linguística moderna, tal como iniciada pelos comparatistas no século XIX e depois por Saussure no século XX, seja contemplada, ela não é considerada como o ponto de início das ciências da linguagem,

${ }^{9}$ Esse estatuto paradoxal pode ser pensado na própria letra do Curso de Linguística Geral. No artigo Proposiçôes e notas para uma leitura de F. de Saussure, Normand (2012, p. 34, grifo nosso) afirma que "se há corte epistemológico, ele se situaria, então, na elaboração do conceito de valor, na medida em que esse conceito se relaciona a todo conjunto de postulados: distinçóes, diacronia-sincronia e língua-fala, definição da língua como sistema. No entanto, o corte permanece como uma hesitação empirista no desenvolvimento desse capitulo. Ele aparece, inicialmente, no emprego repetido dos termos 'entidades (ou unidades) concretas', 'real' (termos insuficientemente definidos em relação à atividade abstrata da análise), e isso justo quando somos encorajados a renunciar ao empirismo. [...] Quando se lê [...] que 'a noção de valor recobre as de unidade', o termo recobre é evidentemente demasiado vago e não dá conta do que nos aparece como uma reformulaçáo dos conceitos (e náo uma simples mudança de termos). O que parece indicar que, lá onde vemos um corte, Saussure (e/ou seus editores) não o via (m) claramente". Em outro direcionamento, em A ferramenta imperfeita, Henry (1992, p. 84, grifo nosso) rejeita o obstáculo (na obra saussuriana) de uma descriçáo semiológica da realidade e o desdobramento da consideração saussuriana da língua como instituição social, em tudo que implica o "apagamento" da problematização teórica do sujeito, do inconsciente e da ideologia: "Rejeitamos a ideia de que o princípio de uma solução esteja na procura de uma semiologia qualquer ou na identificação da língua como uma instituição social (no sentido em que geralmente entende-se essa palavra), vendo nessa solução apenas uma máscara destinada a recalcar a necessidade de um recurso a uma teoria das ideologias e do efeito sujeito cujos projetos náo poderiam ter sido considerados por Saussure dado que dependiam dos cortes produzidos alhures, na obra de Marx e na de Freud". 
que têm uma história bem mais longa e plural. Assim, quando utilizamos o adjetivo linguístico, ele se refere a qualquer saber produzido sobre a linguagem na história. A definição de ciência da linguagem de S. Auroux é suficientemente ampla para abarcar a diversidade de saberes e seu modo de aparecimento no tempo e no espaço (NUNES, 2008, p. 109).

Por um lado, conforme aponta Baldini (2005), a "neutralidade epistemológica" é, com razão, uma crítica frontal a um dos mitos da historiografia da Linguística e das ciências da linguagem que se estabeleceu a partir do século XIX: o mito da cientificidade. Auroux considera que o saber com qual o historiador das ideias linguísticas trabalha é inscrito em longo prazo (ancorado na tradição greco-latina) e é transmitido historicamente por meio das tecnologias ou instrumentos linguísticos. Em outros termos, esse mito de cientificidade combatido por Auroux consistiria na pressuposição de que os estudos da linguagem se iniciaram a partir do comparativismo. Assim, o termo "ciência" não seria tomado em um sentido normativo da linguagem-objeto, mas enquanto palavra meramente descritiva (AUROUX, 2009).

Ressaltamos que as interrogaçóes levantadas tanto pelo campo da História das Ideias Linguísticas quanto pela Análise do Discurso podem ser estendidas à problemática específica do "corte saussuriano", cuja leitura exegética confere frequentemente a centralidade ao conceito de valor.

Uma grande parte da historiografia saussuriana repousa sobre uma certa ideia (um certo mito) de ciência: ela seria descontínua, de acordo com o modelo construído por G. Bachelard, a partir da Física Moderna [...]. Tal modelo retoma o grande estudo de A. Koyré sobre Galileu e as ideias que ele desenvolvia sobre a noção de "revoluçáo científica", o qual tinha a vantagem de romper com a ideia ingênua do século XIX de que a ciência seria uma simples acumulação de "descobertas". Não só isso: ele supunha um "nascimento" da ciência pela "ruptura epistemológica" que separaria, na história das nossas representaçôes, a "verdadeira" ciência da ideologia. Desse fato, o modelo teve o inconveniente de suscitar a descoberta de inumeráveis "rupturas epistemológicas", neste ou naquele domínio do saber. É nesse contexto dos anos sessenta que Saussure foi a vítima ou o "beneficiário" desta moda. Tanto os textos dos linguistas "alemães" (de língua germânica) do século XIX como aqueles de Saussure podiam se prestar muito facilmente a essa abordagem, porque o próprio autor genebrino se via como fundador da verdadeira "ciência" linguística. Antes dele, nada de científica teria sido feito no que se refere à linguagem. Trata-se de um ponto de vista dificilmente admissível, absurdo, para aqueles que possuem um conhecimento aprofundado das disciplinas que têm a linguagem por objeto, saberes cuja origem remonta em torno ao terceiro e ao segundo milênios. 
Entendemos rapidamente que essa visão de ciência não correspondia ao seu funcionamento normal. A partir dos anos cinquenta do século XX, os historiadores da ciência construíram um outro modelo, mais em conformidade com o desenvolvimento de nossos conhecimentos tomados a longo termo. Aplicado a Saussure, o novo modelo implicaria que pudéssemos responder à questão: o que descobriu o linguista, ou, em outras palavras, sobre esse novo conhecimento que ele construiu, o que, efetivamente, se mantém estável na prática do linguista? Nós temos um recuo de cem anos, e nosso método tão, se não mais, antigo, reconhece em Saussure um imenso linguista. Para a revolução científica, é outra coisa; a novidade não introduzia o tanto de descontinuidade que não se pudesse reconhecer os elementos do Antigo Regime no Novo, nem entrever, no Antigo, o que iria se passar (AUROUX, 2017, p. 170).

Apesar de rejeitar a ideia de "revolução científica", Auroux afirma que Saussure é um grande cientista e que o conceito de valor pode ser considerado como núcleo de racionalidade que possibilita a deduçáo de todo seu sistema conceitual:

\footnotetext{
Saussure é um cientista de grande envergadura e autor de múltiplas inovaçôes, entre as quais, algumas são de grande invenção. Se fosse preciso avaliá-las, eu optaria incontestavelmente por colocar o "valor" em primeiro plano, até porque o resto pode muito bem ser deduzido (mesmo se não se trata certamente da ordem da descoberta). Que essa invenção surja em um núcleo de racionalidade presente em uma série muito longa, não somente coloca luz no processo normal de evoluçáo do conhecimento, mas, sobretudo, faz da força teórica surpreendente de Saussure diferença na realidade mesma do elemento (AUROUX, 2017, p. 196).
}

Do ponto de vista da Análise do Discurso, podemos ler em Gadet, Léon, Maldidier e Plon ([1990] 1997, p. 40) que, desde a época da publicação de Análise Automática do Discurso (1969), Pêcheux é um leitor atento de Saussure. Para os autores, as leituras do Curso de Linguística Geral, das Sources (fontes manuscritas) de Godel, dos anagramas (via Starobinski) e dos Nibelugen podem ser sentidas no trabalho de Pêcheux em sua concepção de língua, em seu posicionamento relativo a algumas distinçóes tidas como radicais em sua época e o papel analítico atribuído ao efeito metafórico. Essas concepçóes e posicionamentos são construídos, sobretudo, a partir de uma rede de alianças e dissoluçôes teóricas de Pêcheux com outros leitores de Saussure na paisagem teórica dos anos 60 e 70. Sobre a concepção de "efeito metafórico" nos trabalhos iniciais de Pêcheux, os autores apontam: 
O papel atribuído ao efeito metafórico. Certamente influenciado pela leitura de Jakobson (par metáfora/metonímia tal como é apresentado em "Linguística e Poética"), mas talvez, acima de tudo, pela compreensão de uma posição saussuriana sobre a língua, que parece dever algo ao mesmo tempo ao conceito de valor è convivência com os Anagramas (GADET; LÉON; MALDIDIER; PLON ([1990] 1997, p. 42, grifo nosso).

Se os autores apontam que é na noção de efeito metafórico da AAD69 que Pêcheux parte de uma concepçáo saussuriana de língua, ao mesmo tempo, ligada ao conceito de valor e ao convívio com os manuscritos de Saussure sobre "literatura" (ou "poética"), é somente no texto "A semântica e o corte saussuriano: língua, linguagem, discurso" (1971) que o autor apresentará uma referência às lendas germânicas, em nota de rodapé à formulação (hoje clássica) de que "o princípio da subordinação da significaçâo ao valor pode ser considerado como o centro da ruptura saussuriana" (HAROCHE; HENRY; PÊCHEUX, [1971] 2007, p. 17, grifo dos autores).

Citemos essa nota:

Esse princípio [do primado do valor sobre a significação] parece ter preocupado Saussure durante toda a sua vida. Notas pessoais sobre as personagens das mitologias germânicas, bem anteriores ao Curso, atestam tal afirmaçáo. Ver Godel, R. "Les sources manuscrites du 'Cours de Linguistique Générale' de Ferdinand de Saussure”, Genève, Droz e Paris : Minard, 1957 (HAROCHE; HENRY; PÊCHEUX, [1971] 2007, p. 17).

O legado saussuriano produziu diferentes efeitos no percurso intelectual de Pêcheux, em um espaço em que se operaram demarcaçôes, retornos, repetiçóes e derivas. Náo podemos pensar os efeitos do corte saussuriano sem que sejamos imediatamente capturados por uma série de direcionamentos históricos e institucionalizados de sentidos, de interpretaçốes desse $\operatorname{arquivo~}^{10}$. Para Pereira de Castro e Behares (2010), ao tocarmos na questão do legado de Saussure, é possível expor uma região de confrontos e contatos que, ao invés de mostrar fragilidades na reflexão do autor, ressalta seu aspec-

\footnotetext{
${ }^{10}$ A partir da concepção de Pêcheux ([1982] 2010, p. 51), compreendermos o arquivo "como um campo de documentos pertinentes e disponíveis sobre uma questáo”. Para nós, mais do que colocar somente a disponibilidade e a pertinência dos documentos em questáo, Pêcheux assinala que o arquivo se constitui pelas polêmicas formas de leitura. Além disso, não é possível, na Análise do Discurso, partir de "fatos" transparentes ao olhar, na medida em que o gesto de leitura é parte constitutiva do trabalho do analista frente ao processo de construção, descrição e interpretação do arquivo.
} 
to surpreendente.

Da mesma forma, Orlandi (2005) também adverte que não é possível pensar a trajetória de Pêcheux de forma linear, estanque e evolutiva. Seguindo essa orientaçáo, Petri (2006) destaca a importância de relacionarmos a fundação da Análise do Discurso com o percurso de Pêcheux, levando em conta os esquecimentos, os silenciamentos, as lacunas e as saturaçóes:

Falar do passado é tentar estabelecer elos com a memória, tentando evitar que essa recuperação da memória se reduza a um acúmulo de informaçōes sobre o passado. Estamos, na verdade, construindo aqui um "gesto de interpretação" sobre fatos que são, por sua própria natureza, lacunares, e, portanto, devem ser lidos de forma não-linear. Importa produzir o efeito de presentificação de um passado que vem revelar nuances da história de um homem [Pêcheux] que, muitas vezes, se confunde com a própria história da teoria do discurso, que vem funcionar nos estudos da linguagem, tal como são concebidos hoje no Brasil. Nos interessa abordar um pouco da história da fundaçấo da Análise do Discurso $(\mathrm{AD})$, levando em conta que a recuperaçấo de traços de memória revela também os esquecimentos, os silenciamentos, as lacunas, as saturaçōes. Estamos lançando um olhar sobre essa história, trata-se de um ponto de vista que, seguramente, poderia ser outro e ainda assim estaria revelando traços importantes da história da fundação da Teoria do Discurso, tal como foi pensada naquela época (PETRI, 2006, p. 1-2).

Partindo da premissa de que toda interpretação marca uma tomada de posição, consideramos também que nosso arquivo deve ser construído tendo em vista a problemática da leitura, o funcionamento histórico e discursivo da noção de autor e obra e dos modos de estruturação dos horizontes de retrospecção como parte da enunciação científica. A noção de arquivo nos deixa diante da questão fundamental, a pergunta aparentemente simples: o que é ler? O que seria olhar para a opacidade do arquivo-Saussure na produção de Pêcheux, e, em especial, quais foram os efeitos e o lugar do "corte saussuriano" nessa trajetória intelectual? Se relacionarmos as posições da História das Ideias Linguísticas e da Análise do Discurso, como podemos compreender hoje a problemática do "corte saussuriano" e do efeito-Saussure (PÊCHEUX, [1982] 1998) no corpo sócio-histórico da Linguística?

Para concluir, a História das Ideias Linguísticas nos ensina que a longa tradição da transmissão do saber linguístico não é cumulativa (COLOMBAT; FOURNIER; PUECH, 2010). De acordo com Colombat, Founier e Puech (2010), em um domínio de saber dado, existe, sobretudo, uma tensão contraditória entre duração e descontinuidade, tensão que aqui exploramos 
no confronto entre teorias. De um lado, há pontos nodais de estabilidade, como noçóes ou conceitos, teorias e, frequentemente, fragmentos de teorias, que têm sua permanência assinalada; de outro, tais conceitos e teorias dependem dos sistemas históricos de representação emergentes em que estão inseridos. Os dois "fenômenos" (permanência e mudança) colocam questōes teóricas e metodológicas diferentes. Nesse sentido, os trabalhos de Puech $(2005 ; 2006 ; 2008 ; 2013)$ nos instigam a pensar futuramente como a categoria "historiográfica" de "recente" demanda uma leitura particular, envolvendo questóes como, por exemplo, o conjunto de debates acerca da "autonomia" da Linguística, a ideia historicamente situada de refundação da Linguística e das ciências humanas e sociais pela "herança" saussuriana, as diferentes versôes do(s) estruturalismo(s) desde a década de 1920, os destinos do saussurianismo e o processo de disciplinarização da linguística em instituiçóes específicas.

\section{Referências}

ALTHUSSER, Louis. De O Capital à filosofia de Marx. In: ALTHUSSER, Louis; RANCIÈRE, Jacques; MACHEREY, Pierre. Ler o Capital: volume 1. Rio de janeiro: Zahar, 1979. p. 11-74.

O objeto de O Capital. In: ALTHUSSER, Louis; BALIBAR, Étienne; ESTABLET, Roger. Ler o Capital: volume 2. Rio de janeiro: Zahar, 1980. p. 7-147.

AUROUX, Sylvain. A revoluçáo tecnológica da gramatizaçáo. 2. ed. Campinas: Unicamp, 2009.

O que pode dizer um historiador da ciência sobre Saussure? Entremeios: Revista de Estudos do Discurso, v. 15, p. 169-196, jul./dez. 2017. Disponível em: <http://www.entremeios.inf.br/published/531.pdf >. Acesso em: 15 jul. 2018. 
BALDINI, Lauro. Um linguista na terra da gramática. 2005. Tese (Doutorado em Linguística) - Universidade Estadual de Campinas, Unicamp. 2005.

BALIBAR, Étienne; PÊCHEUX, Michel. Definiçôes. In: FICHANT, Michel; PÊCHEUX, Michel. Sobre a história das ciências. Lisboa: Estampa, [1969] 1971. p. 11-16.

COLOMBAT, Bernard; FOURNIER, Jean-Marie; PUECH, Christian. Histoire des idées sur le langage et les langues. Paris : Klincksieck, 2010.

DISCUSSION (IV. Les Philosophes «devant» les sciences humaines). Linx (Les sciences humaines : quelle histoire?/!. Actes du colloque de Mai 1980 de Paris X - Nanterre), hors-série n. 2, p. 388-418, 1980. Disponível em: $<$ https://www.persee.fr/doc/linx_0246-8743_1980_hos_1_2_1545>. Acesso em: 12 jul. 2018.

ENGELS, Friedrich. Prefácio à $3^{a}$ edição [de 1885] à obra O 18 de brumário de Luís Bonaparte. In: MARX, Karl. $\mathbf{O} 18$ de brumário de Luís Bonaparte. São Paulo: Boitempo, 2011, p. 21-22.

GADET, Françoise; LÉON, Jacqueline; MALDIDIER, Denise; PLON, Michel. Apresentação da conjuntura em linguística, em psicanálise e em informática aplicada ao estudo dos textos na França em 1969. In: GADET, Françoise; HAK, Tony (Org.). Por uma análise automática do discurso: uma introdução à obra de Michel Pêcheux. Campinas: Unicamp, [1990] 1997, p. 39-58.

GADET, Françoise; PÊCHEUX, Michel. La linguistique hors d'elle-même: l'histoire absolument. Actes du colloque «L'histoire des sciences humaines : pourquoi et comment ?", Nanterre, Presses de l'Université, 1980, p. 360-369. 
HAROCHE, Claudine; HENRY, Paul; PÊCHEUX, Michel. A semântica e o corte saussuriano: língua, linguagem, discurso. In: BARONAS, Roberto Leiser (Org.). Análise do discurso: apontamentos para uma história da noção-conceito de formação discursiva. São Carlos: Pedro \& João, [1971] 2007, p. 13-32.

HENRY, Paul. A ferramenta imperfeita: língua, sujeito e discurso. Campinas: Unicamp, 1992.

. Os fundamentos teóricos da "análise automática do discurso" de Michel Pêcheux (1969). In: GADET, Françoise; HAK, Tony (Org.). Por uma análise automática do discurso: uma introdução à obra de Michel Pêcheux. Campinas: Unicamp, 1997, p. 13-38.

HERBERT, Thomas [Michel Pêcheux]. Reflexôes sobre a situação teórica das ciências sociais e, especialmente, da psicologia social. In: PÊCHEUX, Michel. Análise de Discurso: textos selecionados por Eni Puccinelli Orlandi. Campinas: Pontes, [1966] 2011, p. 21-54.

MALDIDIER, Denise. Elementos para uma história da análise do discurso na França. In: ORLANDI, Eni (Org.). Gestos de leitura: da história no discurso. 3. ed. Campinas: Unicamp, 2010, p. 9-22.

NORMAND, Claudine. Proposiçóes e notas para uma leitura de F. de Saussure. In: . Convite à linguística. São Paulo: Contexto, 2012, p. $23-46$.

NUNES, José Horta. Uma articulação da análise de discurso com a história das ideias linguísticas. Letras, n. 37, p. 107-124, 2008.

ORLANDI, Eni. Discurso e texto: formulação e circulação dos sentidos. Campinas: Pontes, 2005. 
PÊCHEUX, Michel As ciências humanas e o "momento atual". Análise do discurso: textos selecionados por Eni Puccinelli Orlandi. Campinas: Pontes, [1969] 2011. p. 175-202.

Análise automática do discurso (AAD69). In: GADET, Françoise; HAK, Tony (Org.). Por uma análise automática do discurso: uma introdução à obra de Michel Pêcheux. Campinas: Unicamp, [1969] 1997, p. 61-162.

. Ideologia e história das ciências: os efeitos do corte galilaico na Física e na Biologia. In: FICHANT, Michel; PÊCHEUX, Michel. Sobre a história das ciências. Lisboa: Estampa, [1969] 1971, p. 17-58.

. Ler o arquivo hoje. In: ORLANDI, Eni (Org.). Gestos de leitura: da história no discurso. 3. ed. Campinas: Unicamp, [1982] 2010, p. 49-60.

Semântica e discurso: uma crítica à afirmação do óbvio. 2. ed. Campinas: Pontes, [1975] 1995.

Sobre a (des-)construção das teorias linguísticas. Línguas e Instrumentos Linguísticos, Campinas, n. 2, p. 7-32, jul./dez. [1982] 1998.

PÊCHEUX, Michel; GADET, Françoise. Há uma via para a linguística fora do logicismo e do sociologismo? Análise de discurso: textos selecionados por Eni Puccinelli Orlandi. Campinas: Pontes, [1977] 2011. p. 295-310.

PEREIRA DE CASTRO, Maria Fausta; BEHARES, Luis. Apresentação. Caderno de Estudos Linguísticos, v. 1, n. 52, p. 7-9, 2010.

PETRI, Verli. Michel Pêcheux e a teoria do discurso nos anos 60. Expressáo, v. 1, p. 186-192, 2006.

PUECH, Christian. L'émergence de la notion de " discours " en France et les destins du saussurisme. Langages : Les genres de la parole, v. 39, n. 159, p. 93-110, 2005. 
L'esprit de Saussure : reception et héritage (l'héritage linguistique saussurien : Paris contre Genève). Les dossiers de HEL, n. 3, 2013. Disponível em: <http://htl.linguist.univparis-diderot.fr/num3/puech.pdf>. Acesso em: 10 jul. 2018.

Pour une histoire de la linguistique dans l'histoire de la linguistique ? Histoire Épistémologie Langage, v. 28, n. 28-1, p. 9-24, 2006.

Qu'est-ce que faire l'histoire du "récent " ? In : DURAND, J. ; HABERT, B. ; LAKS, B. (Org.). Congrès Mondial de Linguistique Française : Histoire, épistémologie, réflexivité. Paris : Institut de Linguistique Française, 2008. p. 1093-1102.

Recebido: 23/11/2018

Aceito: $17 / 12 / 2018$

DOI: $10.5902 / 2179219435763$ 